INTERVENTIONAL CARDIOLOGY AND SURGERY

\title{
Coronary angiography in patients undergoing carotid artery stenting shows a high incidence of significant coronary artery disease
}

\author{
R Hofmann, A Kypta, C Steinwender, K Kerschner, M Grund, F Leisch
}

See end of article for authors' affiliations

Correspondence to: Dr Robert Hofmann, Cardiovascular Division, City Hospital Linz, Krankenhausstrasse 9, A4020 Linz, Austria; robert. hofmann@akh.linz.at

Accepted

24 November 2004

Published Online First 10 March 2005

\begin{abstract}
Objective: To assess the incidence, morphology, and associated clinical symptoms of coronary artery disease in patients undergoing elective carotid artery stenting.

Methods: In a prospective observational study at a tertiary care centre (university teaching hospital) 444 consecutive patients underwent elective stenting of the carotid artery. Twenty four patients had to be ruled out because of urgent carotid intervention for severe neurological symptoms, lack of compliance, complications from vascular puncture, or renal failure. In 390 patients, the coronary angiography was performed together with carotid artery stenting in a single session; the remaining 30 patients have had a recent coronary angiography.

Results: One, two, and three vessel disease and left main stenoses were found in 70 (17\%), 64 (15\%), 93 $(22 \%)$, and $31(7 \%)$ patients, respectively. Sixty six $(16 \%)$ patients had a history of coronary artery disease but no current significant stenosis. Only $39 \%$ of the patients with significant stenoses $(n=258)$ had clinical cardiac symptoms.

Conclusions: For patients undergoing elective stenting of the carotid, routine coronary angiography reliably discloses morphologically significant coronary artery disease and enables consecutive treatment in $61 \%$ and $29 \%$. This safe measure is useful because a majority of patients with a significant stenosis are asymptomatic.
\end{abstract}

$\mathrm{T}$ e coincidence of stroke in patients with coronary artery patients and, conversely, myocardial infarction in patients with neurological disease is well known. ${ }^{1-3}$ These seemingly connected clinical events account for many fatal complications of intervention. ${ }^{13}$ Knowledge of concomitant coronary artery disease and comprehension of the eventual absence of coronary symptoms in severely diseased patients would probably increase the safety of carotid artery stenting in the aging patient population. It was, therefore, the purpose of our study to analyse systematically the coronary arteries in all, even asymptomatic, patients undergoing routine carotid artery stenting in our institution.

\section{METHODS}

From July 1998 to January 2004, in our institution 444 patients underwent elective stenting of the internal carotid artery. According to our research protocol, the carotid artery was stented in asymptomatic patients with $\geqslant 80 \%$ stenosis of the extracranial carotid artery and in symptomatic patients with $\geqslant 60 \%$ stenosis. Only 10 patients were referred for surgical endarterectomy or treated conservatively because of severe circumferential calcifications or variations of the aortic arch. Patients were referred from our internal and neurological department, from local general practitioners, or from other hospitals. Every patient underwent an independent neurological examination before, 24 hours after, and 30 days after carotid artery stenting. In addition, a positive history of concomitant coronary artery disease was recorded and all patients were thoroughly checked and questioned for symptoms of either typical angina pectoris or chest pain. Angina severity at baseline was classified according to the Canadian Cardiovascular Society classification. ${ }^{4}$ A proven history of coronary artery disease was defined either as a previously angiographically documented coronary artery disease according to the criteria used in the present study (see below) or as a history of myocardial infarction treated in a hospital with a discharge letter available to confirm the diagnosis. Exercise stress tests were not performed systematically before the procedures. After the first 40 carotid artery procedures, for all patients without recent coronary angiography ( $<3$ months), a coronary angiography was attempted in a single session immediately before carotid artery stenting.

The following conditions were defined as contraindications and accounted for 24 patients who did not undergo a simultaneous coronary angiography: urgent carotid artery stenting for severe neurological symptoms, lack of compliance, complications from vascular puncture, and renal failure.

The final study population consisted of 420 patients: for 30 patients a recent angiogram was available; for the other 390 patients coronary angiography was performed in a single session immediately before carotid artery stenting. Table 1 lists the clinical demographic data.

All data were collected prospectively. Written informed consent was obtained from each patient, and the study was approved by our institutional review board.

\section{Carotid artery angiography and stenting}

At least two projections of the carotid artery stenosis were obtained for the calculations of vessel diameter and degree of stenosis. Our interventional procedures has followed the guidelines of good clinical practice with routine use of protective devices since July $2002 .^{5}$

Coronary angiography was possible in all projected patients without complications and was routinely performed before carotid artery stenting. For complete visualisation of the left coronary artery system at least four different projections were used. For complete visualisation of the right coronary artery at least standard left and right anterior oblique projections were obtained. The degree of a stenosis was initially 
Table 1 Clinical characteristics of patients with and without coronary artery disease (CAD)

\begin{tabular}{llll}
\hline & With CAD & $\begin{array}{l}\text { Without } \\
\text { CAD }\end{array}$ & p Value \\
\hline Number of patients & 324 & 96 & \\
Age (years) & $69(9)$ & $69(9)$ & NS \\
Male sex & $216(66 \%)$ & $60(63 \%)$ & NS \\
Hypertension & $246(75 \%)$ & $60(63 \%)$ & 0.0034 \\
Diabetes & $94(29 \%)$ & $24(25 \%)$ & NS \\
Congestive heart failure & $42(13 \%)$ & $2(2 \%)$ & 0.0022 \\
Current smoking & $43(13 \%)$ & $11(11 \%)$ & NS \\
Hypercholesterolaemia & $225(69 \%)$ & $57(59 \%)$ & 0.049 \\
Peripheral vascular disease & $66(20 \%)$ & $5(5 \%)$ & 0.0005 \\
Atrial fibrillation & $45(14 \%)$ & $14(15 \%)$ & NS \\
Neurological symptoms & & & \\
$\quad$ Stroke & $21(6 \%)$ & $14(15 \%)$ & NS \\
Transitory attack & $102(31 \%)$ & $27(28 \%)$ & NS \\
$\quad$ Non-specific symptoms & $57(18 \%)$ & $12(13 \%)$ & NS \\
Asymptomatic & $144(45 \%)$ & $43(44 \%)$ & NS \\
\hline
\end{tabular}

Data are mean (SD) or number (\%).

NS, not significant

estimated by the operator to facilitate an immediate onsite decision about the necessity of percutaneous coronary intervention. For statistical analysis, all visually estimated lesions of $\geqslant 50 \%$ were calculated after the procedure with the use of a semiautomatic device (Hicor, Siemens). Only those measurements were taken for analysis in the present study. The criterion for angiographic one, two, or three vessel coronary artery obstruction was either $a \geqslant 70 \%$ reduction of the internal diameter of the right or left anterior descending or the left circumflex coronary artery or a $\geqslant 50 \%$ reduction of the internal diameter of the left main coronary artery. ${ }^{6}$ In patients with previous coronary artery bypass grafting a graft stenosis, just like a native vessel stenosis, was defined as $\geqslant 70 \%$.

\section{Coronary artery interventions}

The sequence of interventions was based on clinical symptoms of the patient. ${ }^{7}$ Usually a routine coronary angiography was followed by angiography and subsequent intervention of the carotid artery. Percutaneous coronary intervention was carried out last. In patients presenting in Canadian Cardiovascular Society class IV, the percutaneous coronary intervention was performed before the carotid artery was stented. In 12 patients with stenoses in other extracoronary vessels, angiography and stenting of these lesions were carried out last. All procedures were performed by three experienced cardiologists.

\section{Statistical analysis}

All variables were summarised as frequency distributions for categorical variables and mean (SD) for continuous variables. Groups (coronary artery disease or non-coronary artery disease) were compared by the Mann-Whitney $U$ test for continuous variables and $\chi^{2}$ test for categorical variables. Probability values of $p \leqslant 0.05$ were considered significant.

\section{RESULTS}

Table 2 shows the results of carotid artery stenting. The rates of success and neurological complications were not significantly different between patients with and patients without concomitant coronary artery disease. One patient had a nonST elevation myocardial infarction (maximum rise of creatine kinase $\mathrm{MB}$ fraction $29 \mathrm{U} / \mathrm{l}$ ) resulting from occlusion of a small side branch during simultaneous percutaneous coronary intervention.

Coronary artery disease was present in $324(77 \%)$ patients of the study population. Sixty six $(16 \%)$ patients had a
Table 2 Results and complications of carotid artery stenting

\begin{tabular}{|c|c|c|c|}
\hline & With CAD & $\begin{array}{l}\text { Without } \\
\text { CAD }\end{array}$ & p Value \\
\hline Number of patients & 324 & 96 & \\
\hline Technical success & $318(98 \%)$ & $92(96 \%)$ & NS \\
\hline \multicolumn{4}{|l|}{ Neurological complications } \\
\hline Death & $2(0.6 \%)$ & 0 & NS \\
\hline Major stroke & $2(0.6 \%)$ & $2(2 \%)$ & NS \\
\hline Minor stroke & $2(0.6 \%)$ & $2(2 \%)$ & NS \\
\hline \multicolumn{4}{|l|}{ Cardiac complications } \\
\hline NSTEMI & $1(0.3 \%)$ & 0 & NS \\
\hline $\begin{array}{l}\text { Inguinal haematoma requiring } \\
\text { transfusion }\end{array}$ & $3(0.9 \%)$ & $1(1 \%)$ & NS \\
\hline
\end{tabular}

Table 3 Clinical symptoms in patients with significant coronary artery stenosis

\begin{tabular}{llllllll}
\hline & & \multicolumn{5}{c}{ Diseased vessels } & \\
\cline { 3 - 6 } & All patients & $\mathbf{1}$ & $\mathbf{2}$ & $\mathbf{3}$ & LM & p Value \\
\hline All patients & 258 & 70 & 64 & 93 & 31 & \\
No clinical symptoms & $157(61 \%)$ & 43 & 42 & 58 & 14 & NS \\
CCS class & $58(22 \%)$ & 16 & 16 & 21 & 5 & NS \\
II & $30(12 \%)$ & 7 & 5 & 7 & 11 & NS \\
III & $13(5 \%)$ & 4 & 1 & 7 & 1 & NS \\
IV & & & & & & &
\end{tabular}

history of proven coronary artery disease but no current significant stenosis. Most of these had either had successful percutaneous coronary intervention without restenosis or coronary artery bypass grafting with open non-stenotic grafts to diseased vessels. Among 258 patients with at least one significant stenosis 93 were previously known to have coronary artery disease, whereas in 165 patients coronary artery disease was detected during coronary angiography. Table 3 summarises the coronary artery morphology. Among patient with coronary artery disease, three vessel disease was found most often. In addition, a significant stenosis of the main stem of the left coronary artery was not uncommon.

Hypertension, congestive heart failure, peripheral arterial occlusive disease, and hypercholesterolaemia, but not diabetes or current smoking, were significantly more often found in patients with concomitant coronary artery disease than in patients without (table 1).

Table 3 lists clinical cardiac symptoms. Interestingly, 157 of 258 patients $(61 \%)$ with a significant stenosis documented during coronary angiography had no clinical symptoms of coronary artery disease. Clinical symptoms were similar in patients with single vessel, two vessel, and three vessel disease. However, patients with left main coronary artery disease had significantly more often Canadian Cardiovascular Society class III angina $(\mathrm{p}<0.01)$.

Location and morphology of the carotid artery stenoses were not significantly different between patients with and patients without coronary artery disease. The degree (84.4 $(9.3) \% \quad v \quad 85.1 \quad(9.6) \%$ ) and length (11.3 (3.8) $\mathrm{mm} v 11.7$ (5) $\mathrm{mm}$ ) of carotid artery stenosis was similar in patients with and without concomitant coronary artery disease.

\section{Treatment of coronary artery disease}

In summary, $123(48 \%)$ of 258 patients underwent an intervention $(41 \%)$ or surgery $(7 \%)$ and the rest were treated conservatively. In $78 \%$ (82 of 105 patients) undergoing percutaneous coronary intervention the procedure was performed in a single session with carotid artery stenting. 


\section{DISCUSSION}

This is the first report of prospective determination of the presence and extent of coronary artery disease in patients undergoing carotid artery stenting. In 420 consecutive patients undergoing stenting for clinically significant stenosis of the carotid artery, coronary arteries were investigated angiographically. The incidence of significant stenoses was surprisingly high. With respect to good clinical practice, $29 \%$ of all consecutively examined patients had an indication for intervention. The high number of patients with coronary artery disease seems reasonable in the light of the advanced age and frequent co-morbidity of our patient population.

In the past, some authors have reported on neurological complications occurring in connection with coronary artery bypass grafting or myocardial infarctions complicating endarterectomy of carotid artery stenoses. ${ }^{8-10}$ Doppler flow investigations of the carotid artery rather than invasive data were used in most of the studies. Angiographic data regarding the coincidence of carotid and coronary artery disease are limited to non-prospective observational data with a limited number of patients. Consequently, the best method or sequence of surgical treatment of carotid artery stenoses and coronary artery disease has been discussed. ${ }^{11-15}$ As stenting of the carotid artery is replacing surgery more and more, the number of publications concerning carotid artery stenting in the presence of coronary artery disease is increasing as well. ${ }^{16} \mathrm{~A}$ few authors reported on simultaneous stenting of the carotid artery and coronary arteries. ${ }^{77-20}$ Patients undergoing carotid artery stenting seem to be older and more often affected by a clinically significant comorbidity than are patients undergoing surgical endarterectomy. This clinical observation is confirmed by the considerably high number of NASCET (North American symptomatic carotid endarterectomy trial) ineligible patients undergoing carotid artery stenting in several studies. ${ }^{18}{ }^{21}$ Thus, information about the coronary artery disease seems to be of clinical importance, especially for this patient population.

The search for specific risk factors or co-morbidities that may aid speculation about concomitant coronary artery disease in patients undergoing carotid artery stenting without typical symptoms of coronary artery disease does not seem to be clinically accurate. Consistent with findings of other authors, in our study most of the common risk factors were associated with a higher incidence of concomitant coronary artery disease, ${ }^{22} 23$ but only symptomatic peripheral artery occlusive disease was more common in patients with coronary artery disease (table 1). Several years ago, Vigneswaran $e^{2}$ al $^{24}$ did a small study that suggested a higher incidence of left main disease than of three vessel disease not involving the left main stem in patients with significant carotid artery stenoses. However, our own data cannot support this observation.

More strikingly, in the present patient population exercise angina and even the presence of severe coronary symptoms did not correlate with more extensive coronary disease. In other words, in this specific patient cohort it seems impossible to judge the extent of coronary artery disease just by a patient's clinical presentation. To a certain extent, these specific findings may be explained by the morbidity and lack of physical activity in our patient cohort, as physically active patients may experience symptoms before inactive patients do.

The clinical importance of our findings is obvious: patients undergoing elective stenting of the carotid artery have a high incidence of concomitant coronary artery disease. Consistently performed routine coronary angiography has been proved to be a safe method with high diagnostic efficiency and promises to be a useful tool to avoid unexpected cardiac complications during stenting of the carotid artery.

\section{Limitations}

Patients scheduled for carotid artery stenting tend to be older than patients referred for surgical endarterectomy. Thus, the percentage of patients with concomitant coronary artery disease in the present cohort may be higher than in the overall patient population with carotid artery stenosis. The number may also be affected by the cardiological nature of our department, which not only treats patients referred from outside but also recruits them from our own specific patient population.

\section{Authors' affiliations}

R Hofmann, A Kypta, C Steinwender, K Kerschner, M Grund, F Leisch, Cardiovascular Division, City Hospital Linz, Linz, Austria

\section{REFERENCES}

1 Cotter G, Cannon CP, McCabe CH, et al, OPUS-TIMI 16 Investigators. Prior peripheral arterial disease and cerebrovascular disease are independent predictors of adverse outcome in patients with acute coronary syndromes: are we doing enough, Results from the orbofiban in patients with unstable coronary syndromes-thrombolysis in myocardial infarction (OPUS-TIMI) 16 study. Am Heart J 2003; 145:622-7.

2 Goldstein LB. Extracranial carotid artery stenosis. Stroke 2003;34:2767-73.

3 Hirotani T, Kameda T, Kumamoto T, et al. Stroke after coronary bypass grafting in patients with cerebrovascular disease. Ann Thorac Surg 2000;70:1571-6.

4 Campeau L. Grading of angina pectoris. Circulation 1976:54:522-3.

5 Kypta A, Kerschner K, Hofmann R, et al. Single center experience with the carotid artery stent: a 5-year perspective. Z Kardiol 2003;10:249-56.

6 Emond M, Mock MB, Davis KB, and participants in the coronary artery surgery study, et al. Long-term survival of medically treated patients in the coronary artery surgery study (CASS) registry. Circulation 1994;90:2645-57.

7 Hofmann R, Kerschner K, Kypta K, et al. Simultaneous stenting of the carotid artery and other coronary or extracoronary arteries: does a combined procedure increase the risk of interventional therapy? Catheter Cardiovasc Interv 2003;60:314-9.

8 Naylor AR, Mehta Z, Rothwell PM, et al. Carotid artery disease and stroke during coronary artery bypass: a critical review of the literature. Eur J Vasc Endovasc Surg 2002;23:283-94.

9 Reynolds MW, Zhao SZ, Ross S. Adverse events in coronary artery bypass graft (coronary artery bypass grafting) trials: a systematic review and analysis. Heart 2003;89:767-72.

10 Gates PC, Eliasziw M, Algra A. Identifying patients with symptomatic carotid artery disease at high and low risk of severe myocardial infarction and cardiac death. Stroke 2002;33:2413-6.

11 Darling RC 3rd, Dylewski M, Chang BB, et al. Combined carotid endarterectomy and coronary artery bypass grafting does not increase the risk of perioperative stroke. Cardiovasc Surg 1998;6:448-52.

12 Kaul TK, Fields BL, Riggins LS, et al. Coexistent coronary and cerebrovascular disease: results of simultaneous surgical management in specific patient groups. Cardiovasc Surg 2000;8:355-65.

13 Johnson RG. Carotid endarterectomy and coronary artery bypass: the staged approach. Ann Thorac Surg 1998;66:1480-2.

14 Trachiotis GD, Pfister AJ. Management strategy for simultaneous carotid endarterectomy and coronary revascularisation. Ann Thorac Surg 1997;64:1013-8.

15 Borger MA, Fremes SE, Weise RD I, et al. Coronary bypass and carotid endarterectomy: does a combined approach increase risk? A metaanalysis. Ann Thorac Surg 1999;68:14-20.

16 Lopes DK, Mericle RA, Lanzino G, et al. Stent placement for the treatment of occlusive atherosclerotic carotid artery disease in patients with concomitant coronary artery disease. J Neurosurg 2002;96:490-6.

17 Yadav JS, Roubin GS, lyer S, et al. Elective stenting of the extracranial carotid arteries. Circulation 1997;95:376-81.

18 Al-Mubarak N, Roubin GS, Liu MW, et al. Early results of percutaneous intervention for severe coexisting carotid and coronary artery disease. Am J Cardiol 1999;84:600-2.

19 Kiesz RS, Rozek MM, Bouknight D. Bilateral carotid stenting combined with three-vessel percutaneous coronary intervention in single setting. Catheter Cardiovasc Interv 2001;52:100-4.

20 Shawl F, Kadro W, Domanski MJ, et al. Safety and efficacy of elective carotid artery stenting in high-risk patients. J Am Coll Cardiol 2000;35:1721-8.

21 North American Symptomatic Carotid Endarterectomy Trial Collaborators. Beneficial effect of carotid endarterectomy in symptomatic patients with highgrade carotid stenosis. N Engl J Med 1991;325:445-53.

22 Kallikazaros I, Tsioufis C, Sideris S, et al. Carotid artery disease as a marker for the presence of severe coronary artery disease in patients evaluated for chest pain. Stroke 1999;30:1002-7. 
23 Tanne D, Shotan A, Goldbourt U, for the Bezafibrat Infarction Prevention Study Group, et al. Severity of angina pectoris and risk of ischemic stroke. Stroke 2002;33:245-50.
24 Vigneswaran WT, Sapsford RN, Stanbridge RD. Disease of the left main coronary artery: early surgical results and their association with carotid artery stenosis. Br Heart J 1993;70:342-5.

\section{IMAGES IN CARDIOLOGY}

\section{Complete fracture of a right ventricle to pulmonary artery shunt}

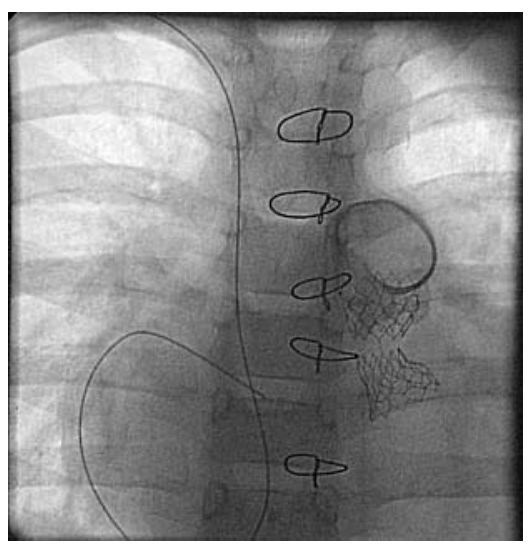

A week old baby boy with type 1 truncus arteriosus had reconstruction of the right $\Delta$ ventricular outflow tract with a $12 \mathrm{~mm}$ aortic homograft. He developed early conduit stenosis, and a $16 \mathrm{~mm}$ aortic homograft was implanted at the age of 30 months. Within 12 months, he again developed severe conduit stenosis. A $27 \mathrm{~mm}$ genesis $(\mathrm{J}+\mathrm{J})$ diameter was implanted at the right ventricular outflow tract with a good angiographic result and a fall in right ventricular pressure from $104 \mathrm{~mm} \mathrm{Hg}$ to $70 \mathrm{~mm} \mathrm{Hg}$. Eight months later, the obstruction had recurred. Fluoroscopy showed complete circumferential fracture of the stent.

Right ventricle to pulmonary artery homografts and biosynthetic conduits frequently develop progressive obstruction. The principal benefit of balloon expandable intravascular stents lies in prolonging conduit life span and decreasing the number of conduit reoperations. Fracture of the stents is a recognised adverse effect, usually identified as an incidental finding on chest $x$ ray, echocardiogram, or fluoroscopy. The main predisposing factor could be caused by external compression between the sternum and aorta. Uneven stresses on stents, wherein the proximal part lies within the right ventricular wall, could also predispose to fracture because of the effect of myocardial compression.

S J Murugan D F Dickinson

J L Gibbs

\section{Hepatopulmonary syndrome as a cause of persistent hypoxaemia}

A 38 year old man, submitted for orthotopic liver transplantation for $\alpha 1$ antitrypsin deficit hepatic cirrhosis, was admitted to the intensive care unit for postoperative monitoring. Ventilatory weaning was difficult because of severe hypoxaemia even using high $\mathrm{FIO}_{2}\left(\mathrm{PaO}_{2}<60 \mathrm{~mm} \mathrm{Hg}\right.$ for $\mathrm{FIO}_{2}$ of 0.7$)$. After extubation the patient remained hypoxaemic with $\mathrm{PaO}_{2}$ of $60 \mathrm{~mm} \mathrm{Hg}$ and breathing 50\% supplementary oxygen. Orthodeoxia was not evident but contrast enhanced transthoracic echocardiography showed delayed microbubble opacification of left heart chambers suggestive of hepatopulmonary syndrome (panels $\mathrm{A}-\mathrm{C}$ ).

Hepatopulmonary syndrome is a pulmonary complication of advanced chronic liver disease, characterised by the presence of severe hypoxaemia $\left(\mathrm{PaO}_{2}<60 \mathrm{~mm} \mathrm{Hg}\right.$ breathing room air), dyspnoea, platypnoea, orthodeoxia, and digital clubbing. The main physiopathologic explanation for the syndrome is the presence of arteriovenous pulmonary shunting related to intrapulmonary vascular abnormalities akin to cutaneous spider angiomata found in cirrhotic patients. These abnormalities are mostly present in the lower pulmonary fields justifying orthodeoxia (a fall in arterial oxygen tension upon assum-

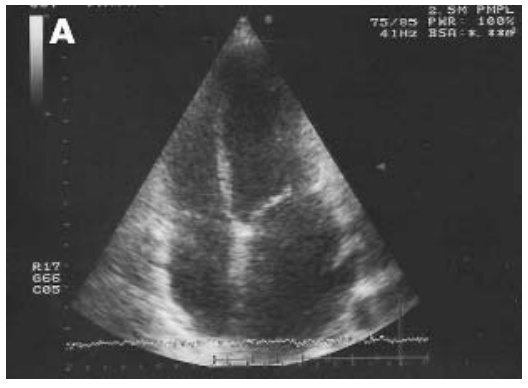

Transthoracic echocardiography in apical view before contrast.

ing an upright position). Hypoxaemia may also be explained by other mechanisms such as perfusion-diffusion defects, failure of hypoxic pulmonary vasoconstriction, change in mediators of vascular dilatation, or rightwards displacement of the $\mathrm{O}_{2}$-haemoglobin dissociation curve.

Up to $80 \%$ of patients with hepatopulmonary syndrome show improvement or resolution 15 months after orthotopic liver transplantation.

A P Fernandes S Marum J P Ribeiro susan.mar@mail.telepac.pt

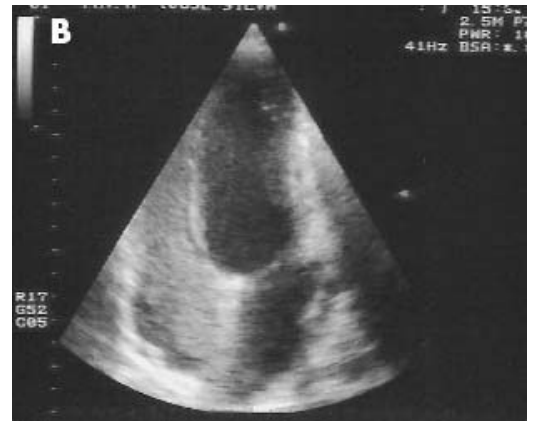

Transthoracic echocardiography in apical view after injection of agitated saline, showing opacification in the right chambers.

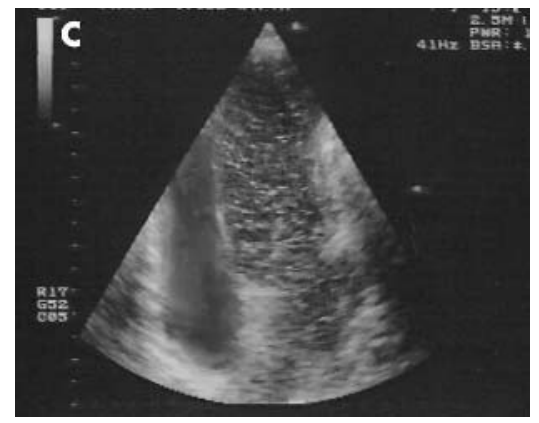

Delayed opacification of left cardiac chambers after saline infusion. 